\title{
Stuttering: an investigation into cerebral dominance for speech
}

\author{
GAVIN ANDREWS, P. T. QUINN, AND W. A. SORBY \\ From the Communication Disorders Laboratory, School of Psychiatry, University of New South Wales and \\ the Department of Diagnostic Radiology, Prince Henry Hospital, Sydney, Australia
}

SUMMARY Over the past decade research has suggested that stutterers have bilateral cerebral motor or auditory speech areas. Three typical adult stutterers showed normal unilateral left cerebral dominance for speech on the intracarotid sodium amylobarbitone (amytal) test, but one 'dysphatic' stutterer had bilateral cortical speech representation. The latter is a very rare finding in right handed individuals and presumably is a consequence of the head injury induced aphasia that preceded the onset of stuttering.

Some $4 \%$ of children stutter, and while most subsequently remit, stuttering persists in about $1 \%$ of the adult population. These individuals can be restricted in their schooling, choice of occupation, and social contacts, and are often exposed to the same psychological stresses as other handicapped individuals. There is neither a generally accepted treatment nor general agreement on aetiology.

In the 1920s and '30s, Orton (1928), Travis (1931), and others developed the concept of stuttering as a manifestation of incomplete cerebral dominance for speech. While evidence available at that time was suggestive (Jasper, 1932; Bryngelson, 1935, 1940; Lindsley, 1940; Douglass, 1943), further research was unable to vindicate this theory and interest in it subsequently dwindled. In the last decade, however, the results of new investigatory techniques have led to renewed interest in the Orton-Travis theory.

Some of Stromsta's (1964) work on the crosscorrellogram analysis of electroencephalograms (EEG) suggests a difference between stutterers and normals in terms of hemispheric dominance. Neaves (1970) has found that stuttering children with a poor prognosis tend to show poor dominance on dexterity tasks. Curry and Gregory (1969) have used the Dichotic Word Task-as developed by Broadbent and Gregory (1964) and Kimura (1967) - to investigate the degree of cerebral dominance for comprehension of meaningful verbal material in stutterers and normals. This test indicates the degree of lateralization of the auditory speech area in the temporal lobe, rather than the motor speech area. Not surprisingly, Kimura has shown that of it correlates well with the dominant hemisphers $\omega$ for motor speech, as determined by the intraథ $\vec{A}$ carotid sodium amylobarbitone (amytal) tes응 (Wada and Rasmussen, 1960). Curry ant Gregory obtained results that could wers indicate lack of cerebral dominance of the auditory speech area in stutterers.

The most dramatic report was published i $\mathrm{i}$ this journal by R. K. Jones (1966). He found that all four stutterers on whom he performed the intracarotid sodium amytal test showed bilateral motor speech areas. Furthermore, all four patients stopped stuttering after surgical injury to one of their presumed speech areas, necessary in the course of managing an unrelated neurological lesion.

One case was a 13 year old left-handed boy with a left frontal astrocytoma. Another was a right-handed 27 year old man with an acute subarachnoid haemorrhage. The other two cases were left-handed adults with subarachnoid haemorrhages.

This work has been influential and has encouraged much recent research into the neurological basis of speech in stutterers. It is obvious that the report of Jones needed to be replicated in stutterers who had no additional cerebral pathology.

This is a report of four stutterers on whom the intracarotid sodium amytal test was performed in order to establish the degree of laterality of the 
cerebral motor speech centres. This test has been used elsewhere to determine the degree of cerebral speech dominance in at least 308 normal speakers (Branch, Milner, and Rasmussen, 1964; Serafetinides, 1965; Milner, Branch, and Rasmussen, 1966; Rossi and Rosadini, 1967). While approximately $15 \%$ of left-handed (and ambidextrous) individuals show bilateral speech centres, such a result has been reported in only three right handers. One of these was a head injured subject reported by Milner et al. (1966), another was reported by Rossi and Rosadini (1967), and the third was the right-handed patient in Jones series (1966).

This suggests that there is about one chance in 300 of a right-handed individual without cerebral pathology having bilateral speech representation as shown by this test. The findings of bilateral speech representation in typical right-handed stutterers would therefore be significant.

\section{METHOD}

The technique used was essentially similar to that described by Wada and Rasmussen (1960), and as used in the large series of Branch et al. (1964). The approach, however, was by percutaneous catheterization of the femoral artery with a Cook polyethylene catheter, and the use of an image intensifier and television screening to enable the positioning of the catheter in the appropriate carotid artery, via the aortic arch. Angiograms using $60 \%$ Urografin were taken to ensure correct positioning of the catheter, and also to preclude any significant crosscirculation to the contralateral hemisphere. With the patient unpremedicated, and counting with his hands held up in the position described by Wada (1960), $200 \mathrm{mg} \mathrm{2} \%$ sodium amylobarbitone (amytal) was injected over two to three seconds. The time duration of the contralateral hemiplegia was established by observing the tone, plantar reflex, and ability of the subject to move his limbs. The catheter was then heparinized and left in place until all sedative effects of the amylobarbitone injection had worn off. This was usually about three hours. When the subject had fully recovered, the test was repeated with the catheter in the other carotid artery.

To determine the degree of dysphasia, the subjects were asked to count, name objects, recite familiar word lists, and describe simple movements carried out by the experimenter. To test comprehension, they were asked to open and close their eyes, squeeze the experimenter's hand, and to stop squeezing to a verbal cue.

The first three subjects (1-3) were young adult males with no evidence of neurological or significant medical disorder, apart from a typical history of stuttering since early childhood. All had been previously treated for their stutter in an intensive three week inpatient course at Prince Henry Hospital, which enjoys a gratifyingly high improvement rate. Despite this generally successful programme, which is based on the use of delayed auditory feedback procedures coupled with a token reward system, these individuals returned with moderately severe stutters, and, after the possible hazards of the procedure were described to them, volunteered for this series of investigations.

The fourth subject was a 35 year old right-handed male who had no personal or family history of stuttering until 1967, at which time he was recovering from aphasia produced by a severe head injury in 1965. At the time of this series this patient had little evidence of residual dysphasia, but had a definite and severe stutter $(20.3 \%$ of all syllables spoken) which showed adaptation and consistency effects, and was characterized more by the repetitions typically heard in a young stutterer, rather than the secondary manifestations found in adult stutterers.

\section{CASE 1}

This 30 year old right-handed male had stuttered since 4 years of age. Stutter was moderately severe.

INJECTION IN RIGHT CAROTID From 4 seconds after injection he remained mute but recommenced counting accurately at 17 seconds and named accurately at 40 seconds. He was still hemiplegic at 60 seconds. Hemiplegia passed off at 2 minutes, 30 seconds.

INJECTION IN LEFT CAROTID $\mathrm{He}$ was mute at 3 seconds and then showed dysphasic speech from 3 minutes, 25 seconds. Objects were named correctly at 4 minutes, 45 seconds; he counted correctly at 6 minutes, 45 seconds and obeyed commands at 1 minute, 30 seconds, and 2 minutes, 35 seconds. He was still hemiplegic at 2 minutes, 50 seconds. Hemiplegia passed off at 7 minutes, 35 seconds.

CONCLUSION Left cerebral hemisphere was dominant for speech.

\section{CASE 2}

This 23 year old right-handed male had stuttered since 5 years of age. Stutter was moderately severe.

INJECTION IN RIGHT CAROTID From 4 seconds after injection he was mute, but he counted correctly at 13 seconds and named objects at 50 seconds. He was still hemiplegic at 1 minute, 45 seconds. Hemiplegia was gone at 2 minutes, 15 seconds.

INJECTION IN LEFT CAROTID He was mute at 3 
seconds. Unintelligible sounds were recorded at 45 seconds and continued until 3 minutes, 15 seconds. There was attempted counting with jargon speech at 3 minutes, 25 seconds. He counted correctly at 5 minutes, 30 seconds and named accurately at 5 minutes, 40 seconds.

He obeyed commands from 40 seconds, including complex commands at 4 minutes, 15 seconds.

He was still hemiplegic at 3 minutes, 35 seconds but hemiplegia was gone at 4 minutes.

CONCLUSION Left cerebral hemisphere was dominant for speech.

CASE 3

This 29 year old right-handed male had stuttered since 4 years of age. Stutter was moderately severe

INJECTION IN RIGHT CAROTID He was mute from 4 seconds after injection. Counting began at 19 seconds.

He named objects at 2 minutes, 5 seconds. Hemiplegia was still present at 5 minutes, 55 seconds but gone at 6 minutes, 50 seconds.

INJECTION IN LEFT CAROTID. He was mute from 3 seconds. He counted correctly at 7 minutes, $10 \mathrm{sec}-$ onds. Dysphasic speech was present at 7 minutes, 45 seconds but he named accurately at 9 minutes, 50 seconds. Commands were obeyed at 1 minute, 30 seconds and on four occasions thereafter.

He was still hemiplegic at 4 minutes, 10 seconds. Hemiplegia was gone at 4 minutes, 45 seconds.

CONCLUSION Left cerebral hemisphere was dominant for speech.

\section{CASE 4}

This 35 year old right-handed male had stuttered since 31 years of age after head injury and consequent aphasia. Stutter was of moderate severity.
INJECTION IN LEFT CAROTID. At 4 seconds he was mute. Unintelligible speech was present at 30 and 을 38 seconds and dysphasic phrasing ('I am...Z I ...') at 50 seconds. Dysphasic speech occurred at 1 minute, 25 seconds; 2 minutes; 2 minutes, 10 seconds. Commands were obeyed at 1 minute, $40 \mathrm{sec}-\frac{\mathrm{C}}{\mathrm{a}}$ onds; 2 minutes, 30 seconds; 3 minutes, 10 seconds. He counted accurately at 2 minutes, 40 seconds. Dysphasic speech was still present at 4 minutes, $\frac{9}{-}$ 55 seconds and he was still hemiplegic at 4 minutes. Hemiplegia was gone at 5 minutes, 35 seconds. He. conversed normally at 7 minutes, 30 seconds.

INJECTION IN RIGHT CAROTID He was mute at? 3 seconds. Commands were obeyed at 40 seconds; $\frac{\bar{D}}{\bar{D}}$

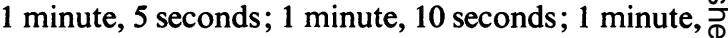
40 seconds. At 2 minutes, 20 seconds, he responded $\cong$ to painful stimulus with purposive movements and कै obeyed commands at 2 minutes, 40 seconds; $\overrightarrow{0}$ 2 minutes, 45 seconds. He responded to painful $\rightarrow$ stimulus at 3 minutes and obeyed commands at $\vec{\omega}$ 3 minutes, 10 seconds, 3 minutes, 20 seconds, 4 minutes. He responded to painful stimuli with dysphasic speech at 4 minutes, 10 seconds, obeyed commands at 5 minutes, and obeyed complex com mand at 5 minutes, 5 seconds. He responded painful stimuli at 5 minutes, 55 seconds.

Hemiplegia was gone at 6 minutes, 25 seconds. Ho counted accurately at 6 minutes, 40 seconds, replieg ? 'no' to question at 7 minutes, 50 seconds and was dysphasic (toy car = 'torch') at 10 minuteg, 30 seconds. He conversed normally at 12 minutes, 30 seconds.

INJECTION IN RIGHT CAROTID (REPEAT 48 HOURS LATER) He was mute at 4 seconds. Unintelligible sounds were recorded at 12-15 seconds and 1822 seconds. He obeyed commands at 35 seconds; $\stackrel{2}{\circ}$ 48 seconds; 1 minute, 25 seconds; 1 minute, $\stackrel{\mathbb{\Omega}}{2}$ 55 seconds; 3 minutes, 45 seconds.

He responded to painful stimulus with dysphasic

TABLE 1

RESULTS OF THE INTRACAROTID AMYLOBARBITONE TESTS IN FOUR PATIENTS

\begin{tabular}{|c|c|c|c|c|c|c|c|}
\hline $\begin{array}{c}\text { Case } \\
\text { no. }\end{array}$ & $\begin{array}{l}\text { Carotid } \\
\text { artery }\end{array}$ & $\begin{array}{l}\text { Mute } \\
\text { period }\end{array}$ & $\begin{array}{c}\text { Period of } \\
\text { dysphasic } \\
\text { speech }\end{array}$ & $\begin{array}{l}\text { Accurate } \\
\text { counting } \\
\text { from }\end{array}$ & $\begin{array}{l}\text { Accurate } \\
\text { naming } \\
\text { from }\end{array}$ & $\begin{array}{l}\text { Ability } \\
\text { to obey } \\
\text { commands }\end{array}$ & $\begin{array}{l}\text { Duration of } \\
\text { hemiplegia }\end{array}$ \\
\hline \multirow[t]{2}{*}{1} & Right & $0.3-0.17$ & - & 0.17 & 0.40 & $0 \cdot 17$ & $2 \cdot 30$ \\
\hline & Left & $0 \cdot 3-3 \cdot 25$ & $3 \cdot 25-4 \cdot 45$ & 6.45 & $4 \cdot 45$ & $1 \cdot 30$ & $7 \cdot 35$ \\
\hline \multirow[t]{2}{*}{2} & Right & $0.4-0.13$ & - & 0.13 & 0.50 & $0 \cdot 13$ & $2 \cdot 15$ \\
\hline & Left & $0.3-0.45$ & $0.45-5 \cdot 30$ & $5 \cdot 30$ & 5.40 & 0.40 & 4.00 \\
\hline \multirow[t]{2}{*}{3} & Right & $0.4-0.19$ & - & 0.19 & $2 \cdot 05$ & $0 \cdot 19$ & $6 \cdot 50$ \\
\hline & Left & $0 \cdot 3-7 \cdot 10$ & - & $7 \cdot 10$ & $9 \cdot 50$ & $1 \cdot 30$ & $4 \cdot 45$ \\
\hline \multirow[t]{3}{*}{4} & Right & $0 \cdot 3-4 \cdot 10$ & $4 \cdot 10-6 \cdot 40$ & 6.40 & $7 \cdot 50$ & 0.40 & $6 \cdot 25$ \\
\hline & Left & $0.4-0.30$ & $0 \cdot 30-2 \cdot 40$ & $2 \cdot 40$ & $7 \cdot 30$ & $1 \cdot 40$ & $5 \cdot 35$ \\
\hline & $\begin{array}{l}\text { Right } \\
\text { (repeat) }\end{array}$ & $0 \cdot 3-0 \cdot 12$ & $0 \cdot 12-3 \cdot 35$ & $3 \cdot 35$ & $4 \cdot 55$ & 0.35 & $3 \cdot 50$ \\
\hline
\end{tabular}

Times are given in minutes and seconds. 
speech and purposive movements at 60 seconds; 2 minutes; 2 minutes, 40 seconds; 3 minutes.

He counted (1-10) at 2 minutes, 35 seconds and replied to question with ' no' at 3 minutes, 50 seconds.

Hemiplegia was gone at 3 minutes, 50 seconds. He gave his home address accurately at 4 minutes, 55 seconds but misnamed the hospital at 5 minutes, 15 seconds.

CONCLUSION Bilateral cerebral speech representation was present.

\section{DISCUSSION}

In no instance did angiography suggest significant cross flow to the contralateral hemisphere. In every case the expected contralateral hemiplegia was produced, and it lasted for a significant period. There was no evidence of ipsilateral hemiplegia. In no instance was there prolonged loss of consciousness. Every subject responded correctly to commands within 90 seconds of injection, either by verbal response when the non-dominant hemisphere was injected, or by specific voluntary movements when the dominant hemisphere for speech was injected.

Observers were impressed by the marked difference in speech in the two to three minutes after injection of the dominant and nondominant hemispheres. The results of each test were clear cut.

Because the cumulative effect of amylobarbitone could not be excluded as a factor in the abnormal response to right hemisphere injection in subject 4, the test was repeated two days later, and an identical result obtained.

Following reports of affect changes in amylobarbitone test subjects, we noted a very mild euphoria after all injections. In no instance was this very marked. No depression was noted.

Walle and Luessenhop (1971) of the Catholic University and Georgetown University Hospital, Washington D.C., have reported using the amytal test on three typical stutterers and found no evidence of bilateral representation of speech. It would appear that in the absence of an adventitial neurological lesion, typical stutterers have no general tendency to show bilateral speech centres as revealed by the intracarotid sodium amylobarbitone test. Despite all safeguards, the test still carries a minimal risk, and so the series was discontinued once a definite result was achieved.

In this series, as in Walle's series, three typical adult stutterers showed no evidence of bilateral speech representation. It is not clear why these results differ from those of Jones (1966). All Jones's patients had intercurrent cerebral pathology. One had an astrocytoma and compensatory bilateralization of speech areas could have occurred. The other three patients, however, had acute subarachnoid haemorrhages and it is difficult to conceive that a reactivation of bilateral speech centres could have occurred so promptly. Three of Jones's cases were left handed, a group which is known to have a $15 \%$ incidence of bilateral speech centres due to chance alone.

The fourth case in the present material is of interest. At the time of his head injury, he presumably had unilateral cerebral speech representation, as only one case of bilateral speech centres has been reported among righthanded individuals who have no cerebral pathology (Rossi and Rosadini, 1967). It is probable that the non-dominant hemisphere was recruited in order to overcome the dysphasia. There is no direct evidence that this change was related to the aetiology of his stutter. It is worth noting that three cases of 'dysphatic' stuttering after left temporal lobe lesions have been reported (Gutzmann, 1921; Froeschels, 1931; and Arend et al. (1962)-quoted by Arend, Handzel, and Weiss, 1962. The head injury sustained in 1965 by the fourth case in this series was extensive and significant left temporal lobe involvement is likely.

Finally, it should be realized that left-handed and ambidextrous individuals show no increased incidence of stuttering (Andrews and Harris, 1964) despite a $15 \%$ incidence of bilateral speech representation in these groups. Furthermore, in those left handers shown to have bilateral speech centres on intracarotid amylobarbitone tests (Rasmussen, 1971; Rossi, 1971), no stuttering was noted.

It would thus appear that the aetiology of stuttering is more obscure than Jones's work suggests. The concept of incomplete cerebral dominance in stutterers is tantalizing and, in terms of auditory speech areas, is still plausible. Nevertheless, this investigation was unable to duplicate Jones' findings of bilateral motor speech areas in stutterers.

\section{REFERENCES}

Andrews, G., and Harris, M. (1964). The Syndrome of Stuttering. (Clinics in Developmental Medicine No. 17.) Heinemann: London.

Arend, R., Handzel, L., and Weiss, B. (1962). Dysphatic stuttering. Folia Phoniatrica, 14, 55-66. 
Beech, H. R., and Fransella, F. (1968). Research and Experiment in Stuttering. Pergamon: Oxford Press.

Branch, C., Milner, B., and Rasmussen, T. (1964). Intracarotid sodium amytal for the lateralization of cerebral speech dominance. Observations in 123 patients. Journal of Neurosurgery, 21, 399-405.

Broadbent, D. E., and Gregory, M. (1964). Accuracy of recognition for speech presented to the right and left ears. Quarterly Journal of Experimental Psychology, 16, 359-360.

Bryngelson, B. (1935). Sidedness as an etiological factor in stuttering. Pedagogical Seminary, Journal of Genetic Psychology, 47, 204-217.

Bryngelson, B. (1940). A study of laterality of stutterers and normal speakers. Journal of Social Psychology, 11, 151-155.

Curry, F. K. and Gregory, H. H. (1969). The performance of stutterers on dichotic listening tasks thought to reflect cerebral dominance. Journal of Speech and Hearing Research, 12, 73-82.

Douglass, L. C. (1943). The study of bilaterally recorded electroencephalograms of adult stutterers. Journal of Experimental Psychology, 32, 247-265.

Jasper, H. H. (1932). A laboratory study of diagnostic indices of bilateral neuro-muscular organization in stutterers and normal speakers. Psychological Monographs, 43, No. 1, 72-174.

Jones, R. K. (1966). Observations on stammering after localized cerebral injury. Journal of Neurology, Neurosurgery, and Psychiatry, 29, 192-195.

Kimura, D. (1967). Functional asymmetry of the brain in dichotic listening. Cortex, 3, 163-178.

Lindsley, D. B. (1940). Bilateral differences in brain potentials from the two cerebral hemispheres in relation to laterality and stuttering. Journal of Experimental Psychology, 26, 211-225.

Milner, B., Branch, C., and Rasmussen, T. (1966). Evidence $Z$ for bilateral speech representation in some non-right- $\mathbb{D}$ handers. Transactions of the American Neurological Association, 91, 306-308.

Neaves, A. (1970). To establish a basis for prognosis in stammering. British Journal of Disorders of Communication, 5, 46-58.

Orton, S. T. (1928). A physiological theory of reading disability and stuttering in children. New England Journal of Medicine, 199, 1046-1052.

Rasmussen, T. (1971). Personal communication.

Rossi, G. F. (1971). Personal communication.

Rossi, G. F., and Rosadini, G. (1967). Experimental analysis of cerebral dominance in man. In Brain Mechanisms Underlying Speech and Language, Proceedings of a Conference held at Princeton, New Jersey, November 9-12, 1965, pp. 167-184. Edited by C. H. Millikan and F. L. Darley. Grune and Stratton: New York.

Serafetinides, E. A., Hoare, R. D., and Driver, M. V. (1965). Intracarotid sodium amylobarbitone and cerebral domin- \$ ance for speech and consciousness. Brain, 88, 107-130.

Stromsta, C. (1964). Preliminary final report. P.H.S. Grant N.B. 03541-03.

Travis, L. E. (1931). Speech Pathology. Appleton: New $\vec{\omega}$ York.

Wada, J., and Rasmussen, T. (1960). Intracarotid injection of sodium amytal for the lateralization of cerebral speech $\overline{7}$ dominance. Experimental and clinical observations. $\omega$ Journal of Neurosurgery, 17, 266-282.

Walle, E., and Luessenhop, A. (1971). Personal communiç tion. 